\title{
Daphnia fitness over a food gradient : is body size the single trait predicting exploitative ability?
}

\author{
J.L. Pereira, F. Gonçalves
}

CESAM \& Department of Biology, University of Aveiro, 3810-193 Aveiro, Portugal.

\begin{abstract}
Phytoplankton dynamics in freshwater ecosystems can be faced as a meaningful natural stressor for its main grazers, and hence constrain bottom-up interactions within the trophic structure of the food-web. Filter-feeding zooplankters, such as Daphnia, cope with resources fluctuations by adjusting their life-history as a function of balances in the energy allocation rules. Additionally, Daphnia populations often withstand interspecific competition within coexisting related species, and it is generally assumed that body size is a strategic trait conditioning exploitative ability and the related competitive advantage of species. The lifehistory responses of one Daphnia magna population and three populations of Daphnia cf longispina to a discrete gradient of algae concentration were assessed. This experiment was focused on (i) how these distinct populations regulate life-history when feeding over low, intermediate and high food-levels; and on (ii) whether the large-bodied D. magna can be better in exploiting resources over the gradient than can the smaller $D$. cf longispina populations. We found evidences that body size might not be the single trait influencing the exploitative ability of related species. The $D$. cf longispina populations were often better than $D$. magna in exploiting different levels of resources, and remarkable differences in fitness were found between these similar-sized individuals within food-level; indeed, these differences were frequently of higher scale than those found between the larger D. magna and any of the D. cf longispina populations.
\end{abstract}

Keywords : Daphnia magna, Daphnia cf longispina, life-history, exploitative ability, body size.

\section{Introduction}

Cladocerans, and specifically those belonging to the genus Daphnia, are widely used as model organisms in aquatic ecology, evolutionary biology and ecotoxicology. These organisms are particularly suitable as experimental organisms i.e. are easy to rear, have short and productive life-cycles, and are cyclical parthenogens (allowing the control genotypic variance within and between experiments). The relevance of cladocerans as model organisms lies also on the ecological key-role played by these populations in the food web dynamics of the pelagic zone; they constitute an important food resource for many fish species and are the main grazers upon the phytoplankton assemblages, therefore assuming a pivotal role in the trophic interactions occurring in freshwater ecosystems (Lampert 2006).

* Corresponding author: E-mail: jpereira@ua.pt
Either externally driven environmental changes or the natural grazing dynamics can affect the phytoplankton composition and/or abundance in lentic water bodies. The way cladoceran populations cope with these fluctuations in resources availability is closely related with their exploitative abilities. Daphnia life-history traits such as time to onset reproduction, net fecundity scores, offspring size/quality, growth, and the related population fitness have been shown to be linked to variations in food availability (Taylor \& Gabriel 1985, Lynch 1989, Tessier \& Consolatti 1991, Glazier 1992, Guisande \& Gliwicz 1992, Taylor \& Gabriel 1992, Boersma \& Vijverberg 1994, Boersma 1995, Trubetskova \& Lampert 1995, Boersma 1997a,b). These reported changes in life-history are likely to be promoted by adjustments in the strategies for the allocation of assimilated energy; i.e. result from the balance of investments in reproduction, growth, and/or maintenance (Kooijman 1986, McCauley et al. 1990, Arendt 1997, Polishchuk \& Vijverberg 2005, Rinke \& Vijverberg 2005). In short, as resources get depressed, daphnids generally disinvest 
in reproduction and start giving priority in energy allocation to growth and/or maintenance in order to ensure longevity and lifetime reproduction.

Interspecific competition for resources among closely related species is common within zooplankton communities, and, according to the resource-ratio theory (Tilman 1980) the better competitor within coexisting organisms would be the species able to keep a positive growth rate at lower resource availability. By addressing interspecific competition between ecologically related species (e.g. zooplankton species), the Size Efficiency Hypothesis (Brooks and Dodson 1965) provided the theoretical grounds to explain the dominance of large-bodied over the smaller zooplankton species, in lakes where predation pressure is low or absent: the food concentration need to permit the population maintenance (where population growth equals zero) should decrease as adult body size of coexisting species increases (Brooks and Dodson 1965, Hall et al. 1979). The influence of body size on the grazing activity, and consequently on Daphnia fitness, has been significantly explored in literature since then. It was shown that largebodied Daphnia species have lower threshold levels for food resources i.e. outcompete coexisting smaller species (e.g. Gliwicz 1990, Kreutzer \& Lampert 1999); greater efficiency in food collection and lower metabolic costs of the larger of related species would theoretically enable them to accrue a competitive advantage under resources-limited environments (Hall et al. 1979). The relationship between body size and exploitative ability at unlimited food resources has also been studied and the same competitive advantage of larger morphs seems to exist (Tessier \& Goulden 1987, Declerck et al. 1997, Tessier et al. 2000). This competitive advantage of the large-bodied of related species is not consensual in the literature, and experimental evidences of opposite patterns have been reported, either considering food shortage or unlimited food supply (Lynch 1979, Tillmann \& Lampert 1984, Stemberger \& Gilbert 1985, Tessier \& Goulden 1987). Remarkable differences in exploitative ability have also been found between species similar in body size and between distinct genotypes within the same species (e.g. Boersma \& Vijverberg 1994, Epp 1996, Tessier et al. 2000, Tessier \& Woodruff 2002).

In the present study, we analysed significant life-history endpoints (particularly those related with fecundity, somatic growth and population growth) of four different Daphnia populations feeding over a discrete food quantity gradient. Moreover, the life-history performance and fitness of the large-bodied Daphnia magna Straus was compared with that of three distinct small-bodied species belonging to the Daphnia longispina Müller complex, in order to address the relationship between body size and exploitation efficiency, and concomitantly analyze whether this relationship changes along the food gradient. By comparing life-history and fitness estimates among the similar-sized $D$. cf longispina populations, and between these populations and D. magna, we intended to access whether the taxa-specific plasticity in life-history traits and fitness can balance the advantage of a larger body size in exploiting resources i.e. whether exploitative ability may be constrained by genotype-specific functional diversity rather than singly by size.

\section{Material and Methods}

Monoclonal bulk cultures of Daphnia magna (clone A sensu Baird et al. 1989), and of three Daphnia cf longispina clonal lineages were reared in the lab, under a 16:8 hr light:dark photoperiod, at a temperature of $20 \pm 2^{\circ} \mathrm{C}$, in synthetic ASTM hardwater medium (AST 1980) supplied with an organic additive $\left(5 \mathrm{~mL} \mathrm{~L}^{-1}\right)$ extracted from the algae Ascophyllum nodosum (Baird et al. 1989). Cultures were renewed every other day and the organisms were fed with Pseudokirchneriella subcapitata (Korshikov) Hindak [cultured in Woods Hole MBL medium (Stein 1973) under a semi-continuous regime at $24: 0 \mathrm{hr}$ light:dark photoperiod and $20 \pm 2^{\circ} \mathrm{C}$ room temperature]. The three $D$. c.f. longispina clonal lineages used in tests were established from fieldcollected samples: (1) clone $\mathrm{M}$ was collected in lake Mira (Mira, centre-northwest of Portugal) and has been maintained in the lab since 2001 (clone EM7 sensu Antunes et al. 2003); (2) clone V resulted from a sample picked in lake Vela (Quiaios, centre-northwest of Portugal) in 2004; (3) clone T was collected in the shallow reservoir Tapada Grande (Mértola, southeast of Portugal) in 2004. The species belonging to the subgenus Hyalodaphnia (commonly called Daphnia longispina group) are genetically well differentiated, however interspecific hybridisation and backcrossing within the group often occurs (Schwenk \& Spaak 1995; Schwenk et al. 2000). High rates of interspecific hybridization, and a high degree of phenotypic plasticity observed in some traits constrain appreciably a morphotype-based classification of the species/taxa within Hyalodaphnia (Schwenk et al. 2000; Billiones et al. 2004). ITS-RFLP techniques (Billiones et al. 2004) confirmed that our clones represent three distinct taxa within the $D$. longispina complex (Petrusek et al. 2005): although all the populations morphologically resemble $D$. longispina (according to Benzie 2005), the genotypes M, V and T 
are consistent with ITS-RFLP patterns and 12S DNA sequences of $D$. galeata $\mathrm{x}$ longispina, D. longispina $\mathrm{x}$ galeata and D. galeata, respectively. Hereinafter, we will refer to the different genotypes as D. longispina $\mathrm{M}$, $\mathrm{V}$ and $\mathrm{T}$ for text clarity convenience.

The effects of different food concentrations in the life-history of the four Daphnia genotypes (D. magna and $D$. longispina $\mathrm{M}, \mathrm{V}$ and $\mathrm{T}$ ) were analysed. The lifehistory endpoints were assessed after a 21- d expo sure of the organisms to several food-levels; in order to standardize procedures and the test design, we generally followed the OECD guideline for reproduction bioassays with Daphnia (OECD 1998). The animals were held during 21 days in $50 \mathrm{~mL}$ glass beakers filled with ASTM hardwater, supplied with the A. nodosum additive. In accordance with the guideline recommendations, renewal occurred every other day and the organisms were fed daily according with the food treatment ranges. Five food-levels were used as treatments in each experiment: $0.0,0.375 \times 10^{5}, 0.75 \times 10^{5}, 1.5 \times 10^{5}$, $3.0 \times 10^{5}$ cells $\mathrm{mL}^{-1}$ of $P$. subcapitata. Ten replicates, with a single individual each, were used within each treatment. All the tests started with newborns ageing less than 24h, born in the bulk cultures between the $3^{\text {rd }}$ and the $5^{\text {th }}$ brood, in order to minimize maternal effects (Barata \& Baird 1998).

The tests were screened daily for eventual mortality and for progeny-related records. When present, offspring were counted and immediately removed. The neonates yielded in the first brood were measured (five individuals per female were used as sample). The body size of the females was estimated immediately after the release of the first brood, and at the beginning and at the end of the test, by extrapolation from the moult exopodite length (Pereira et al. 2004), allowing the calculation of the somatic growth rate (SGR) through the following equation:

$$
\mathrm{SGR}=\left[\ln \left(\mathrm{l}_{\mathrm{f}}\right)-\ln \left(\mathrm{l}_{0}\right)\right] / \Delta \mathrm{t}\left(\text { day }^{-1}\right)
$$

where $1_{\mathrm{f}}$ is final body length $(\mathrm{mm}), \mathrm{l}_{0}$ is initial body length $(\mathrm{mm})$ and $\Delta \mathrm{t}$ is time range (days). All measurements were carried out under a stereoscope (Olympus SZX9). Fecundity- and survival-related data were integrated for the estimation of the per capita rate of population increase $\left(r ;\right.$ day $\left.^{-1}\right)$ through the Euler- Lotka equation:

$$
1=\sum_{i=1}^{n} e^{r x} l_{x} m_{x}
$$

where $\mathrm{x}$ stands for age class (days), $1_{\mathrm{x}}$ for probability of surviving to age $\mathrm{x}$, and $\mathrm{m}_{\mathrm{x}}$ for fecundity at age $\mathrm{x}$.
Uncertainties were estimated following the Jackknife technique (Meyer et al. 1986).

\section{Data analysis}

One-Way Analysis of Variance (ANOVA) was used to compare the life-history responses of each Daphnia population to increasing food-levels (four algae concentrations: $0.375 \times 10^{5}-3.0 \times 10^{5}$ cells $\left.\mathrm{mL}^{-1}\right)$. When applicable, the post-hoc Tukey HSD test was used in order to properly assign statistically different food-treatments (Quinn \& Keough 2002). Given the species-specific differences between $D$. magna and $D$. cf longispina in life-history and our aim of providing a direct comparison between all the taxa, we focused on whether there are relative changes in the endpoints/parameters tested as food quantity varies. The data set was therefore transformed by relating each record to the highest record obtained within species/taxa in each endpoint of interest, considering the four higher food treatments The appropriate arcsine transformation was then applied prior to any statistical procedure (Quinn $\&$ Keough 2002). A two-way ANOVA was used to assess the significance of the effects of food quantity and taxa, as well as of their interaction, on the life-history endpoints and on the population growth rate. The strength of association of each factor and interaction to the ANOVA model was addressed through the calculation of the partial Eta-squared parameter (Pierce et al. 2004). As highly significant interactions were consistently detected, a one-way ANOVA was used within each food-level, to test whether taxa differ from each other depending on the food availability; and when applicable, the Tukey HSD post-hoc test was carried out in order to assign statistically significant differences between taxa within food-level (Quinn \& Keough 2002). All statistical procedures were carried out under significance level $(\alpha)$ of 0.05 .

\section{Results}

If one excludes the treatment where no food was added, mortality was rarely observed in the tests $(10 \%$ for D. magna, $2.5 \%$ for D. longispina $\mathrm{M}$ and $5 \%$ for $D$. longispina $\mathrm{V}$ and $\mathrm{T}$ ), and could never be related with the test treatments. In the treatment where no food (i.e. algae) was added, the proper analysis of the life-history parameters was severely constrained: despite the maintenance of the organic supplement (see 'Material and Methods') along the 21 days of the tests, mortality was 
high (20-40\% depending on the Daphnia population) and the surviving animals were often unable to reproduce, which compromises the statistical analysis of several endpoints. Therefore, data relative to this treatment are occasionally mentioned in the text and are shown in the figures for providing merely indicative information on the effects of starvation, but were not considered for statistics.

As a response to an increasing gradient of food concentration all the tested taxa showed a general amelioration of the overall life-history performances. As the food-level raised the organisms yielded significantly larger offspring broods, often reproduced earlier (Fig.1a, b), and generally recorded significantly higher population growth rates, $\mathrm{r}$ (Fig. $2 \mathrm{~b}$; Table 1). How ever, D. longispina V was found to be an exception: although net fecundity was significantly affected along the food gradient, no significant differences in $r$ were detected between food treatments. Actually, this was the least responsive population to changes in food ration, followed by $D$. longispina T (Fig. 1a, b ; Table 1) : D. longispina $\mathrm{V}$ showed large tolerance to food shortage i.e. only net fecundity (number of neonates yielded per female along the 21 days of the test)suffered a significant impairment as food decreased (Table 1 ); D. longispina $\mathrm{T}$ fecundity and $r$ were significantly impaired whereas none of the other analysed endpoints registered significant changes due to variation in food quantity. Both the fecundity endpoints and the growth rates of $D$. magna suffered changes along the food gradient (Fig. 1 -a-d; Fig. 2 -a, b), which were often statistically significant (Table 1). It seems that this population was the most sensitive to the decrease of food availability, but similarly to $D$. cf longispina populations, net fecundity and $\mathrm{r}$ were more responsive than any of the other analysed endpoints (all food treatments promoted significantly different responses in both endpoints - Table 1). As food increases, D. magna grew faster and followed a consistent pattern in reproducing earlier, although at a slightly smaller size and having slightly smaller neonates (Fig. 1 b-d, Fig. 2 a; Table 1). Endpoints such as age at first reproduction (AFR), size of N1 neonates, and primipara size, were indeed found to be less responsive particularly when considering the D. longispina populations (Table 1). D. longispina $\mathrm{M}$ was the single population anticipating significantly the release of a first brood with smaller neonates as food ration raises.

Under near-starvation conditions (no food added), $D$. magna showed a very low somatic growth rate (SGR) and was unable to reproduce at all, which compromised the calculation of the respective $r$ (Fig. 1a ; Fig. 2a, b)
In addition, very little offspring was yielded by any of the $D$. longispina populations (average fecundity: $0.8,5.2$ and 0.1 neonates for $D$. longispina $\mathrm{M}, \mathrm{V}$ and $\mathrm{T}$, respectively). The concentration-response curves relative to all the remaining endpoints/parameters consistently denote very serious impairment in life-history of all starving $D$. cf longispina populations: slightly smaller females released a first brood of slightly smaller neonates, with a considerable delay when comparing this with any of the other food treatments (Fig. 1b - d) ; somatic growth rates were recorded below 0.04, and population growth rates were found either negative $(D$. longispina $\mathrm{T}$ ) or below 0.2 day $^{-1}$ (Fig. 2a, b).

Regarding food-level and species/taxa as contributing factors to the overall effects observed in life-history endpoints, statistics consistently found highly significant interactions; the single exception to this statistical output was assigned to primipara size, where "Taxa" seems to be the single factor independently contributing to the overall variation (Table 2). In fact, the relative spatial order of taxa changes in the plots as food concentration varies ( Fig. 1e, g, h ; Fig. 2c, d), which graphically resembles the statistically determined interaction (see e.g. D. magna fecundity as a clear picture of this graphical feature). The estimation of the strength of association (partial Eta-squared - Table 2) depicted "Food" as the factor contributing more for the registered effects in Fecundity and $r$. "Taxa" had a higher contribution in explaining the variance of the remaining lifehistory endpoints i.e. AFR and primipara size - where no significant effect of "Food" was actually noticed -, size of N1 neonates and SGR.

When compared to the $D$. cf longispina populations, and despite presenting better overall absolute records in life-history endpoints (Fig. 1a, d ; Fig. 2a, b ), the larger D. magna was never clearly superior in adjusting to the food constraints. Moreover, the differences between $D$. cf longispina populations were often of higher magnitude than those between the large-bodied $D$. magna and any of the small-bodied $D$. cf longispina (see e.g. Fig. 1 e $-0.375 \times 10^{5}$ cells $\mathrm{mL}^{-1}$ ). When regarding the lowest food-level, D. magna was the population yielding the lowest relative number of neonates along the test, and delaying more the release of the first brood (Fig. 1 e, f). D. cf longispina populations feeding in this food-level also differed markedly in between when regarding relative fecundity and age at first reproduction: D. longispina $\mathrm{V}$ showed the highest relative fecundity along the test, and $D$. longispina $\mathrm{T}$ reproduced earlier but recording the lowest relative offspring yield. Statistics was strictly consistent with the observed patterns (Table 3). D. longispina $\mathrm{V}$ started reproduction 


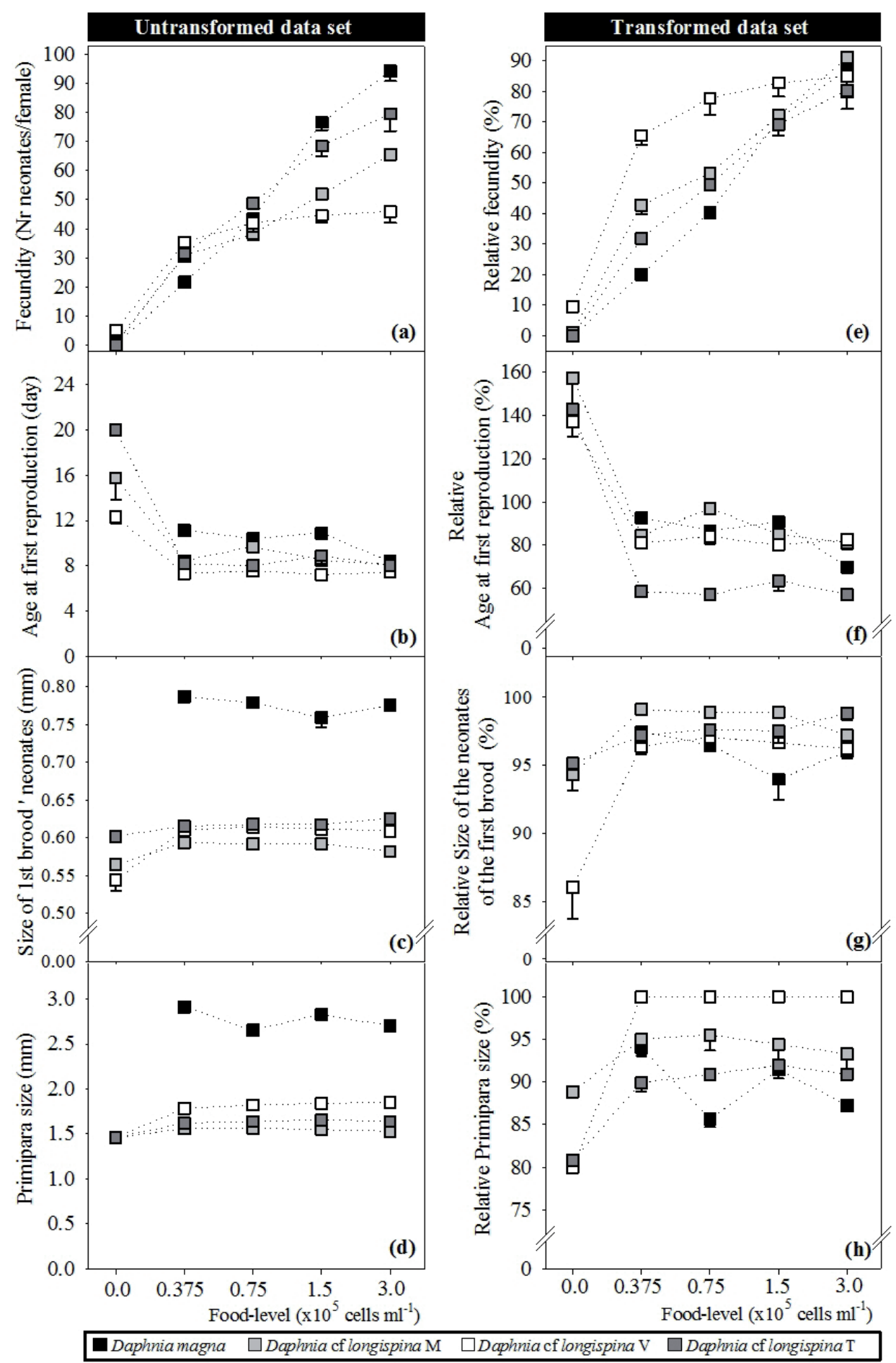

Fig. 1. Life-history responses of Daphnia spp. over a discrete gradient of food concentration: a-d - direct plots obtained from the actual records on the life-history endpoints; e-f - plots regarding the relative changes in the endpoints along the food gradient. Error bars represent the standard error. 


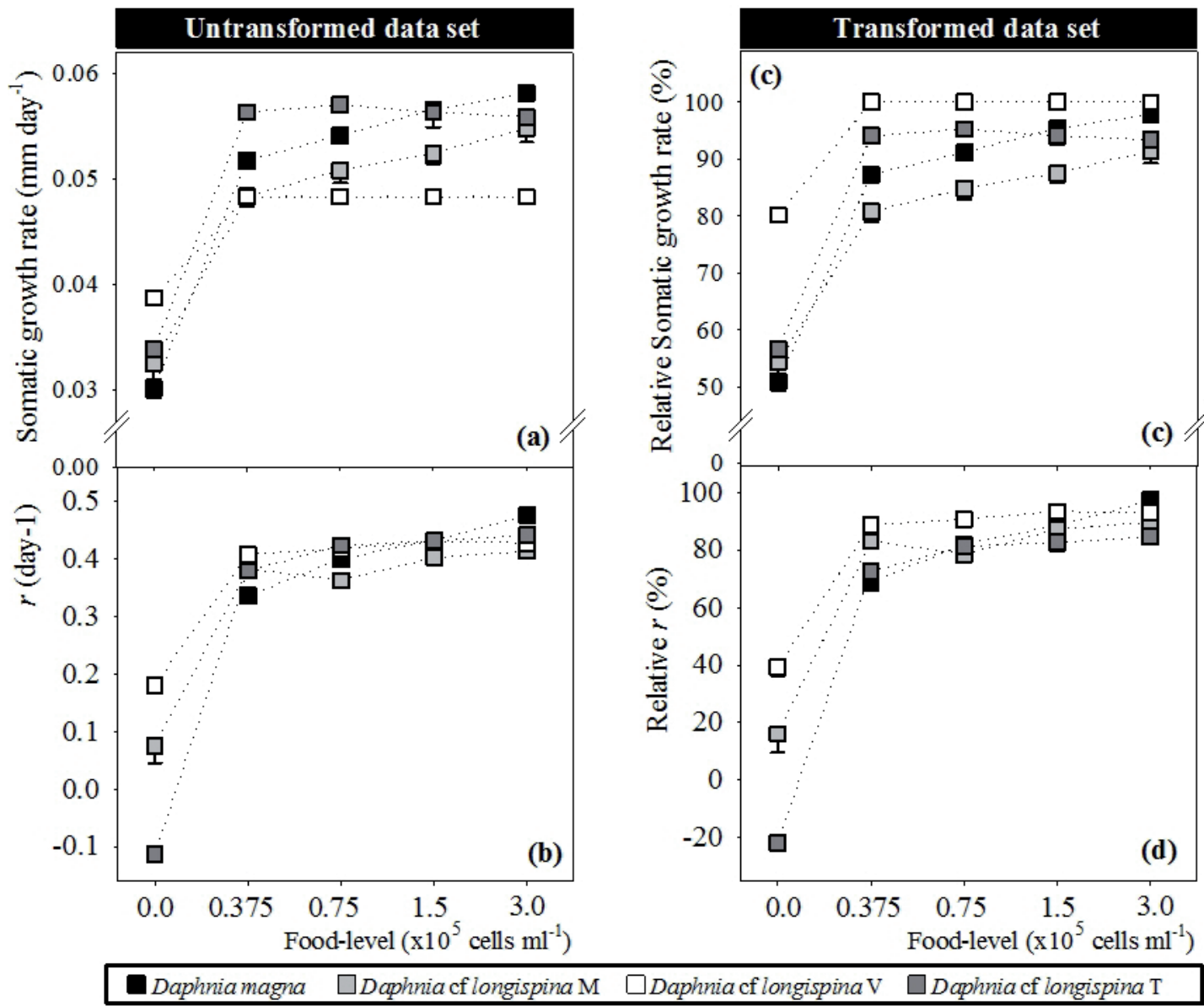

Fig. 2. Somatic- and population growth rates exhibited by the Daphnia populations in response to a discrete food gradient; a, b - direct plots obtained from the actual records made during the experiments; $\mathrm{c}-\mathrm{d}$ - plots regarding the relative changes in the growth parameters along the food gradient. Error bars represent the standard error.

at the largest relative size, followed by D. magna and D. longispina $\mathrm{M}$ that actually did not statistically differ when responding to low food availability; no statistically significant differences were found between the size of the neonates from the first brood released by D. magna, D. longispina $\mathrm{V}$ and D. longispina $\mathrm{T}$ (Fig. $1 \mathrm{~g}$, h; Table 3). As food availability increases these patterns change, and a trend to the smoothing of differences between populations should be noticed (Table 3; Fig. 1 - e-h). Although D. magna and D. longispina T reproduced significantly earlier, the relative fecundity of all populations was statistically similar in the highest food-level; $D$. longispina $\mathrm{T}$ was the single population yielding significantly larger neonates in the first brood under the highest food ration, despite slight differences were found between the primipara sizes of the four populations.

When globally comparing calculated growth rates (SGR and $r$ ) with the remaining life-history endpoints, differences between populations along the entire food gradient seem graphically less marked. The above mentioned trend for a slight smoothing of the graphical distance between populations in the plots as food raises was kept when regarding the somatic growth rate (Fig. 2c): while at $0.375 \times 10^{-5}$ cells $\mathrm{mL}^{-1}$ all populations showed a statistically different somatic growth, at the highest food supply $D$. magna was statistically similar to $D$. longispina $\mathrm{V}$ and $D$. longispina $\mathrm{M}$ did not statistically differed from $D$. longispina $\mathrm{T}$ (Table 3 ). Regardless the food-level, D. longispina $\mathrm{V}$ was always the population 
Table 1. One-Way ANOVA summaries relative to the life-history endpoints analysed within each Daphnia population (df - degrees of freedom; $\mathrm{MS}_{\mathrm{res}}$ - residual Mean Squares; AFR - Age at First Reproduction; SGR - Somatic Growth Rate). Untransformed data were used in this analysis in order to compare food treatments within each Daphnia population. When available, statistically significant differences between food treatments (Tukey test, $\mathrm{P}<0.05$ ) are also assigned in the table, using the letters a-d.

\begin{tabular}{|c|c|c|c|c|c|c|c|c|c|}
\hline & \multirow{2}{*}{ Endpoint } & \multirow{2}{*}{ df } & \multirow{2}{*}{$\mathbf{M S}_{\text {res }}$} & \multirow{2}{*}{$F$ ratio } & \multirow{2}{*}{$P$ value } & \multicolumn{4}{|c|}{ Tukey test [food-levels (cells mL $\left.\mathrm{mL}^{-1}\right)$} \\
\hline & & & & & & $0.375 \times 10^{5}$ & $0.75 \times 10^{5}$ & $1.5 \times 10^{5}$ & \\
\hline \multirow{6}{*}{$\begin{array}{l}5 \\
5 \\
5 \\
0 \\
0\end{array}$} & Fecundity & 3,32 & 44.125 & 208.699 & $<0.001$ & $\mathrm{a}$ & $\mathrm{b}$ & c & d \\
\hline & AFR & 3,32 & 0.252 & 51.258 & $<0.001$ & a & a & a & $\mathrm{b}$ \\
\hline & Size N1 neonates & 3,32 & $4.23 \mathrm{e}^{-4}$ & 2.998 & 0.045 & $\mathrm{a}$ & $a b$ & $\mathrm{~b}$ & $a b$ \\
\hline & Primipara size & 3,32 & 0.0078 & 16.812 & $<0.001$ & $\mathrm{a}$ & $\mathrm{b}$ & $\mathrm{a}$ & $\mathrm{b}$ \\
\hline & SGR & 3,32 & $7.81 \mathrm{e}^{-6}$ & 8.632 & $<0.001$ & $\mathrm{a}$ & $\mathrm{ab}$ & $\mathrm{bc}$ & $\mathrm{c}$ \\
\hline & $r$ & 3,36 & $3.20 \mathrm{e}^{-4}$ & 108.118 & $<0.001$ & $\mathrm{a}$ & $\mathrm{b}$ & $\mathrm{c}$ & $\mathrm{d}$ \\
\hline \multirow{6}{*}{ 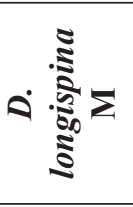 } & Fecundity & 3,35 & 32.542 & 69.910 & $<0.001$ & $\mathrm{a}$ & $\mathrm{b}$ & $\mathrm{c}$ & $\mathrm{d}$ \\
\hline & AFR & 3,35 & 0.849 & 5.725 & 0.003 & $\mathrm{~b}$ & $\mathrm{a}$ & $\mathrm{c}$ & $\mathrm{c}$ \\
\hline & Size N1 neonates & 3,35 & $5.45 \mathrm{e}^{-5}$ & 5.054 & 0.005 & $\mathrm{a}$ & $\mathrm{a}$ & $\mathrm{a}$ & $\mathrm{b}$ \\
\hline & Primipara size & 3,35 & 0.0090 & 0.271 & 0.846 & -- & -- & -- & -- \\
\hline & SGR & 3,35 & $1.30 \mathrm{e}^{-5}$ & 5.362 & 0.004 & $\mathrm{a}$ & $a b$ & $a b$ & $\mathrm{~b}$ \\
\hline & $r$ & 3,36 & $7.74 \mathrm{e}^{-4}$ & 6.453 & 0.001 & $\mathrm{~b}$ & $\mathrm{a}$ & $\mathrm{b}$ & $\mathrm{b}$ \\
\hline \multirow{6}{*}{ 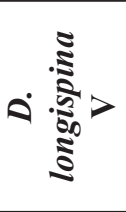 } & Fecundity & 3,34 & 70.335 & 3.053 & $<0.001$ & $\mathrm{a}$ & $\mathrm{ab}$ & $\mathrm{ab}$ & $\mathrm{b}$ \\
\hline & AFR & 3,34 & 0.357 & 0.651 & 0.588 & -- & -- & -- & -- \\
\hline & Size N1 neonates & 3,34 & $1.01 \mathrm{e}^{-4}$ & 0.472 & 0.704 & -- & -- & -- & -- \\
\hline & Primipara size & 3,34 & 0.0034 & 2.407 & 0.084 & -- & -- & -- & -- \\
\hline & SGR & 3,34 & $3.04 \mathrm{e}^{-11}$ & 1.081 & 0.370 & -- & -- & -- & -- \\
\hline & $r$ & 3,36 & $7.59 \mathrm{e}^{-4}$ & 1.325 & 0.281 & -- & -- & -- & -- \\
\hline
\end{tabular}

keeping the highest relative somatic growth records while $D$. longispina $\mathrm{M}$ showed always the slower relative somatic growth rate (Fig. 2c). D. magna was the population having the most severe changes in fitness (i.e. population growth rate, r) along the food gradient; whereas $D$. longispina $\mathrm{T}$ and $D$. longispina $\mathrm{V}$ generally kept the lower and the higher (respectively) fitness values along the food gradient (including in the treatment without food supply), D. magna was not able to sustain the best relative fitness shown at the highest food level when food supply decreases (Fig. 2d; Table 3).

\section{Discussion}

Variations on the availability of food can constitute a relevant environmental stressor of natural communities, representing a direct constrain on the energy uptake and consequently on the energy status of an organism. The dynamics of phytoplankton communities in lentic ecosystems leads to natural fluctuations in resources availability for grazer zooplankters such as Daphnia. Daphnids are known to deal with these resources variation by changing their life-history performances to optimally allocate the available resources
(Guisande \& Gliwicz 1992, Boersma 1997a). Several authors have already stressed that food availability is of main importance for Daphnia reproduction, growth and ultimately survival (e.g. Guisande \& Gliwicz 1992, Boersma 1995, Trubetskova \& Lampert 1995, Epp 1996, Antunes et al. 2003, Polishchuk \& Vijverberg 2005).

Energy and nutrients must be budgeted among different functions in an organism, and resources availability will condition the allocation to a given function often at expenses of a disinvestment in another. The models of energy allocation in starving daphnids by Kooijman (1986) and McCauley et al. (1990), although differing in their mechanistic grounds, assume that maintenance, rather than growth or reproduction, should be the main priority regarding longevity and lifetime reproductive potential. Indeed, experimental evidence supports these models showing that under high food availability daphnids commit a great part of their energy budget to boost reproduction; as food resources depress disinvestment in reproduction and then in growth occurs, and thus smaller females will trade-off smaller broods with larger, e.g. more hunger-resistant, neonates (Tessier \& Consolatti 1991, Glazier 1992, Gliwicz \& Guisande 1992, Taylor \& Gabriel 1992, Trubetskova \& Lampert 1995, Boersma 1997a, Polishchuk \& Vijverberg 
Table 2. Two-Way ANOVA summary relative to the life-history responses of Daphnia feeding on an increasing gradient of food quantity (df degrees of freedom; MS - Mean Squares). The data set was normalised a priori by using the highest record obtained in each endpoint within each population, and the treatment were no food was added was excluded from the analysis. Partial Eta-squared $\left(\right.$ Partial $\left.\eta^{2}\right)$ values were added to the table as a measure of the contribution by each factor and interaction to the overall effects.

\begin{tabular}{|c|c|c|c|c|c|c|}
\hline Endpoint & Source of variation & df & MS & $F$ ratio & $P$ value & Partial $\eta^{2}$ \\
\hline \multirow{3}{*}{ Fecundity } & Food & 3,135 & 2.14173 & 97.22 & 0.000 & 0.684 \\
\hline & Taxa & 3,135 & 0.56486 & 25.64 & 0.000 & 0.363 \\
\hline & Food $\times$ Taxa & 9,135 & 0.08416 & 3.82 & 0.000 & 0.203 \\
\hline \multirow{3}{*}{$\begin{array}{l}\text { Age at first } \\
\text { reproduction }\end{array}$} & Food & 3,135 & 0.14570 & 8.42 & 0.000 & 0.158 \\
\hline & Taxa & 3,135 & 1.02778 & 59.38 & 0.000 & 0.569 \\
\hline & Food x Taxa & 9,135 & 0.09678 & 5.59 & 0.000 & 0.272 \\
\hline \multirow{3}{*}{ Size of N1 neonates } & Food & 3,135 & 0.00175 & 0.40 & 0.757 & 0.009 \\
\hline & Taxa & 3,135 & 0.07144 & 16.16 & 0.000 & 0.264 \\
\hline & Food x Taxa & 9,135 & 0.01208 & 2.73 & 0.006 & 0.154 \\
\hline \multirow{3}{*}{ Primipara size } & Food & 3,135 & 0.01029 & 0.914 & 0.436 & 0.020 \\
\hline & Taxa & 3,135 & 0.18946 & 16.83 & 0.000 & 0.272 \\
\hline & Food x Taxa & 9,135 & 0.01981 & 1.76 & 0.082 & 0.105 \\
\hline \multirow{3}{*}{$\begin{array}{l}\text { Somatic Growth } \\
\text { Rate }\end{array}$} & Food & 3,135 & 0.08809 & 13.65 & 0.000 & 0.233 \\
\hline & Taxa & 3,135 & 0.86431 & 133.89 & 0.000 & 0.748 \\
\hline & Food x Taxa & 9,135 & 0.04317 & 6.69 & 0.000 & 0.308 \\
\hline \multirow{3}{*}{$r$} & Food & 3,144 & 0.28487 & 33.16 & 0.000 & 0.409 \\
\hline & Taxa & 3,144 & 0.19995 & 23.28 & 0.000 & 0.327 \\
\hline & Food x Taxa & 9,144 & 0.05731 & 6.67 & 0.000 & 0.294 \\
\hline
\end{tabular}

Table 3. One-Way ANOVA summaries relative to the life-history endpoints analysed within each food-level (df - degrees of freedom; MS residual Mean Squares; AFR - Age at First Reproduction; SGR - Somatic Growth Rate). Data normalisation was undertaken prior to analysis, as specified in Table 2, and the post-hoc Tukey test was used, when applicable, to assign differences between taxa responding to each food ration (letters a-d in the table).

\begin{tabular}{|c|c|c|c|c|c|c|c|c|c|}
\hline \multirow{2}{*}{ Food Treatment } & \multirow{2}{*}{ Endpoint } & \multirow{2}{*}{ df } & \multirow{2}{*}{$\mathbf{M S}_{\text {res }}$} & \multirow{2}{*}{$F$ ratio } & \multirow{2}{*}{$P$ value } & \multicolumn{4}{|c|}{ Tukey test (Taxa) } \\
\hline & & & & & & $D m$ & $D l \mathrm{M}$ & $D l \mathrm{~V}$ & $D l \mathrm{~T}$ \\
\hline \multirow{6}{*}{$\begin{array}{l}0.375 \times 10^{5} \\
\text { cells } \mathrm{mL}^{-1}\end{array}$} & Fecundity & 3,34 & 0.00556 & 72.373 & $<0.001$ & $\mathrm{~b}$ & $\mathrm{~d}$ & $\mathrm{a}$ & $\mathrm{c}$ \\
\hline & AFR & 3,34 & 0.0142 & 24.796 & $<0.001$ & $\mathrm{a}$ & $\mathrm{ab}$ & $\mathrm{b}$ & $\mathrm{c}$ \\
\hline & Sz N1 neonates & 3,34 & 0.00302 & 7.718 & $<0.001$ & $\mathrm{~b}$ & $\mathrm{a}$ & $\mathrm{b}$ & $\mathrm{b}$ \\
\hline & Primipara size & 3,34 & 0.0110 & 6.185 & 0.002 & $\mathrm{ab}$ & a & $\mathrm{b}$ & $\mathrm{b}$ \\
\hline & SGR & 3,34 & 0.00121 & 305.921 & $<0.001$ & $\mathrm{c}$ & $\mathrm{d}$ & $\mathrm{a}$ & $\mathrm{b}$ \\
\hline & $r$ & 3,36 & 0.00671 & 20.788 & $<0.001$ & $\mathrm{~b}$ & $\mathrm{a}$ & $\mathrm{a}$ & $\mathrm{b}$ \\
\hline \multirow{6}{*}{$\begin{array}{l}0.75 \times 10^{5} \\
\text { cells } \mathrm{mL}^{-1}\end{array}$} & Fecundity & 3,35 & 0.0156 & 20.728 & $<0.001$ & $\mathrm{~b}$ & $\mathrm{~b}$ & $\mathrm{a}$ & $\mathrm{b}$ \\
\hline & AFR & 3,35 & 0.0177 & 36.180 & $<0.001$ & $\mathrm{~b}$ & $\mathrm{a}$ & $\mathrm{b}$ & $\mathrm{c}$ \\
\hline & Sz N1 neonates & 3,35 & 0.00387 & 4.526 & 0.009 & b & $\mathrm{a}$ & a & a \\
\hline & Primipara size & 3,35 & 0.0084 & 13.248 & $<0.001$ & $\mathrm{~b}$ & a & $\mathrm{b}$ & $\mathrm{b}$ \\
\hline & SGR & 3,35 & 0.00499 & 53.469 & $<0.001$ & c & $\mathrm{d}$ & $\mathrm{a}$ & $\mathrm{b}$ \\
\hline & $r$ & 3,36 & 0.00686 & 11.620 & $<0.001$ & $\mathrm{~b}$ & $\mathrm{~b}$ & a & $\mathrm{b}$ \\
\hline \multirow{6}{*}{$\begin{array}{l}1.5 \times 10^{5} \\
\text { cells } \mathrm{mL}^{-1}\end{array}$} & Fecundity & 3,34 & 0.0189 & 4.327 & 0.011 & $\mathrm{~b}$ & $\mathrm{~b}$ & $\mathrm{a}$ & $\mathrm{b}$ \\
\hline & AFR & 3,34 & 0.0270 & 6.514 & 0.001 & $\mathrm{a}$ & $\mathrm{a}$ & $a b$ & $\mathrm{~b}$ \\
\hline & Sz N1 neonates & 3,34 & 0.00712 & 4.947 & 0.006 & b & $\mathrm{a}$ & $\mathrm{a}$ & $\mathrm{a}$ \\
\hline & Primipara size & 3,34 & 0.0142 & 2.136 & 0.114 & -- & -- & -- & -- \\
\hline & SGR & 3,34 & 0.00797 & 27.424 & $<0.001$ & $\mathrm{~b}$ & $\mathrm{c}$ & $\mathrm{a}$ & $\mathrm{bc}$ \\
\hline & $r$ & 3,36 & 0.0132 & 2.876 & 0.049 & $a b$ & $a b$ & $\mathrm{a}$ & $\mathrm{b}$ \\
\hline \multirow{6}{*}{$\begin{array}{l}3.0 \times 10^{5} \\
\text { cells } \mathrm{mL}^{-1}\end{array}$} & Fecundity & 3,32 & 0.0498 & 0.600 & 0.620 & -- & -- & -- & -- \\
\hline & AFR & 3,32 & 0.00983 & 18.094 & $<0.001$ & $\mathrm{~b}$ & $\mathrm{a}$ & $\mathrm{a}$ & $\mathrm{c}$ \\
\hline & Sz N1 neonates & 3,32 & 0.00365 & 8.257 & $<0.001$ & $\mathrm{~b}$ & $\mathrm{~b}$ & $\mathrm{~b}$ & $\mathrm{a}$ \\
\hline & Primipara size & 3,32 & 0.0115 & 3.566 & 0.025 & $\mathrm{~b}$ & $\mathrm{a}$ & $\mathrm{ab}$ & $a b$ \\
\hline & SGR & 3,32 & 0.0120 & 11.939 & $<0.001$ & $\mathrm{a}$ & $\mathrm{b}$ & $\mathrm{a}$ & $\mathrm{b}$ \\
\hline & $r$ & 3,36 & 0.00763 & 15.045 & $<0.001$ & $\mathrm{a}$ & $\mathrm{bc}$ & $\mathrm{ab}$ & $\mathrm{c}$ \\
\hline
\end{tabular}


2005). Our results were generally consistent with these energy allocation models/patterns. All taxa showed better reproductive performances as food raised. Along with food shortage the Daphnia populations would first disinvest in reproduction and would try to keep growth, although at slower rates. Starving Daphnia (no food supply) showed very poor offspring production and growth rates, which provides a clear picture of the extreme situation where maintenance of body condition becomes single priority.

Tessier \& Consolatti (1991) found that Daphnia are able to adapt mean neonate size in response to food density, whereas Glazier (1992) proposed a model attempting to overcame existing experimental controversy on the relationship between egg/offspring size and food availability. When no food was added the D. longispina populations (D. magna was not able to reproduce at all) seem to respond in agreement with this latter model by producing very small offspring due to a reproductive constraint; when food was added, however, only weak inferences could be made on the fit of our experimental results to either model since the size of the neonates released in the first brood, as well as primipara size, rarely changed significantly along the food gradient. Indeed, the relationship between food availability and egg/neonate size and/or quality is not unequivocal nor consistent with theoretical predictions: egg mass was already found to be similar in Daphnia raised at different food rations (Taylor \& Gabriel 1985), and despite not finding differences in size between offspring born under different food-levels, Tessier \& Consolatti (1991) reported higher quality offspring at low food-levels; Boersma (1995) reported smaller but higher-quality neonates produced by $D$. galeata feeding on low foodlevels, but this pattern was not confirmed by the author with D. magna (Boersma 1997b). Our results convey no patterns for remarkable variation in offspring size as a function of food concentration (at least under the tested food range). Similarly, primipara did not differ expressively in size along the food gradient which is in agreement with previous studies (e.g. Kooijman 1986, Lynch 1989, Rinke \& Vijverberg 2005). This independence of primipara body size on food availability is attributed to the existence of a critical size for the onset of reproductive investment (Lynch 1989) and hence food concentration would rather influence the time need to reach that size.

The intrinsic rate of population increase $(r)$ integrates reproductive endpoints and survival, and can therefore be faced as a measure of the populations' fitness (Kammenga et al. 1996); it provides a more feasible estimate of the general ecological impacts of environ- mental changes in natural populations, such as fluctuating food resources, than do the individual-level lifehistory endpoints (Kammenga et al. 1996; Forbes \& Calow 1999). The fitness of the Daphnia populations was responsive to changes in food availability. When facing food shortage, daphnids generally lowered their population growth rates, which is a documented pattern in several organisms and it is likely to be a consequence of an effort to maximise the efficiency of resources use (see the review by Arendt 1997). Given the residual mortality observed in our study, the main contributions for the population growth rates would be the fecundity rates and the time that daphnids take to release the first brood (Meyer 1986, Vanni \& Lampert 1992). Changes in these reproductive endpoints with food-level, due to shifting and/or adjustment in energy allocation strategies (see above) seem though to be of importance on population fitness.

The relationship between exploitative ability of cladoceran species and body size has been faced as evidence of the Size Efficiency Hypothesis postulates (Brooks \& Dodson 1965, Hall et al. 1976): when competing for food resources, small-bodied daphnids would be eliminated by the larger forms, which should be related to a more efficient food collection and a relatively reduced metabolic demand per unit of body mass of the latter. Evidences exist of the advantage of largebodied cladocerans in exploiting low-food conditions i.e. of the increase of food threshold concentration with body size (Gliwicz 1990, Kreutzer \& Lampert 1999). Competitive advantage of larger morphs of similar species feeding in unlimited/high-level food resources was also documented (Tillmann \& Lampert 1984, Tessier \& Goulden 1987, Declerck et al. 1997, Tessier et al. 2000, Tessier et al. 2001) and seems to be related with their higher filtering rates and broad food particle size range (e.g. Declerck et al. 1997, Tessier et al. 2001). Our results were not generally consistent with these trends: when comparing $D$. magna with the $D$. longispina populations within food-level, the large-bodied species was rarely found to be the more effective species in taking advantage of the food resources; and, D. magna only showed the best records when considering the highest food-level and only for growth rates (somatic growth rates and $r$ ) i.e. the small-bodied Daphnia c.f longispina populations were often better in exploiting food resources regardless its level of availability or the endpoint of interest.

In fact, there is some experimental controversy regarding the insight on exploitative competition by the Size Efficiency Hypothesis. In a field study, Lynch (1979) has indeed registered the superiority of smaller spe- 
cies in lakes where size-specific predation was absent. In their experiments with differently-sized daphnids, Tillmann \& Lampert (1984) found that, despite inferior under unlimited resources, the smaller organisms were better competitors given they were able to reproduce even when facing food scarcity. Tessier and Goulden (1987) recorded the specific juvenile growth and showed that, under low food-levels, small body size seems advantageous. Important differences in exploitative ability were also already evidenced, either considering similar-sized species (Boersma \& Vijverberg 1994; Tessier \& Woodruff 2002) or even different genotypes of the same species (e.g. Epp 1996, Tessier et al. 2000, Antunes et al. 2003). Regarding our specific experimental design, Daphnia species followed these patterns rather than those predicted by the Size Efficiency Hypothesis. The smaller $D$. longispina showed better reproductive performance and fitness than D. magna, along the food gradient, denoting that there is no apparent relationship between body size and sensitivity to food availability and/or exploitative ability. This can be related with differential plasticity in life-history traits (Tessier \& Woodruff 2002) and/or rely on a number of physiological features of smaller species that can compensate for body size: (i) higher specific rate of food collection and higher feeding efficiency that are likely to compensate for greater metabolic requirements (DeMott 1982, Stemberger \& Gilbert 1985); (ii) better swimming abilities on a mass-specific basis that can enhance food collection efficiency (Stemberger \& Gilbert 1985); (iii) higher efficiency in energy allocation strategies in face of food gradients (Tessier et al. 1983, Tillmann \& Lampert 1984, Tessier \& Consolatti 1991).

On the other hand, remarkable differences in fitness and life-history within food-level were found between the closely-related and similarly-sized $D$. longispina populations; these differences were frequently higher than those between the larger D. magna and each of the D. longispina populations. This provides evidence that exploitative ability, and eventually competitive ability, may be driven by genotype specificity rather than have a straight relationship with body size. Assuming $r$ as an efficient measure of the populations' fitness (Kammenga et al. 1996) D. longispina $\mathrm{T}$ and $\mathrm{V}$ should be noted as the populations generally withstanding worse and better, respectively, the changes in food availability. In fact, either $D$. longispina $\mathrm{M}$ and $\mathrm{V}$ are interspecific hybrids between species belonging $D$. longispina complex (see 'Material and Methods' for details). The temporal superiority of hybrid genotypes relatively to that of parental species seems to be common and a frequently prevalent phenomenon within Daphnia assemblages where both coexist (Schwenk \& Spaak 1995; Temporal Hybrid Superiority Hypothesis). Here, it seems that additional evidence was generated on the apparent exploitative superiority of hybrid genotypes upon the parental species along a gradient of food concentration.

\section{Conclusion}

This study apparently contradicts one of the assumptions of the Size Efficiency Hypothesis by recognising substantial variation in life-history responses and fitness of different Daphnia species/taxa to food avail ability, regardless differences or similarities in body size. Body size should not be the single trait conditioning exploitative ability within cladoceran communities. Functional diversity in species responses to changes in resource availability seems to result from evolutionary feedbacks to ecological demands; selection will favour genotypes that can better cope with changing environmental conditions (food concentration) by having e.g. more efficient energy allocation strategies that actually can compensate for body size advantages. Functional traits should hence be additionally considered when modelling interspecific competition and community structure of Daphnia assemblages.

\section{Acknowledgements}

J. L. Pereira was supported by a PhD grant from Fundação para a Ciência e Tecnologia (SFRH/BD/13682/2003).

\section{References}

Antunes S.C., Castro B.B. \& Gonçalves F. 2003. - Chronic responses of different clones of Daphnia longispina (field an ephippia) to different food-levels. Acta Oecol., 24, S325-S332.

Arendt J.D. 1997. - Adaptive intrinsic growth rates: an integration across taxa. Q. Rev. Biol., 72, 149-177.

ASTM 1980. - Standard practice for conducting acute toxicity tests with fishes, macroinvertebrates and amphibians. Report E 729-80. American Society for Testing \& Materials, Philadelphia.

Baird D.J., Soares A.M.V.M., Girling A., Barber I., Bradley M.C. \& Calow P.1989. - The long-term maintenance of Daphnia magna Straus for use in ecotoxicity tests: problems and prospects. Pages 144-148 in Proceedings of the First European Conference on Ecotoxicology. Lokke H., Tyle H. \& Bro-Rasmussen F. (eds.). Lyngby.

Barata C. \& Baird D.J. 1998. - Phenotypic plasticity and constancy of life-history traits in laboratory clones of Daphnia magna Straus: effects of neonatal length. Funct. Ecol., 12, 442-452.

Benzie J.A.H. 2005. - The genus Daphnia (including Daphniopsis) - Guides to the identification of the Microinvertebrates of the Continental Water of the World (Vol 21). Kenobi productions, Ghent \& Backhuys Publishers, Leiden, $376 \mathrm{p}$.

Billiones R., Brehm M., Klee J. \& Schwenk K. 2004. - Genetic identification of Hyalodaphnia species. Hydrobiologia, 526, 43-53. 
Boersma M. \& Vijverberg J. 1994. - Resource depression in Daphnia galeata, Daphnia cucullata and their interspecific hybrid: lifehistory consequences. J. Plankton Res., 16, 1741-1758.

Boersma M. 1995. - The allocation of resources to reproduction in Daphnia galeata: against the odds? Ecology, 76, 1251-1261.

Boersma M. 1997a. - Offspring size and parental fitness in Daphnia magna. Evol. Ecol. 11, 439-450.

Boersma M. 1997b. - Offspring size in Daphnia: does it pay to be overweight? Hydrobiologia, 360, 79-88.

Brooks J.L. \& Dodson S.I. 1965. - Predation, body size, and composition of plankton. Science, 150, 28-35.

Burns C.W. 2000. - Crowding-induced changes in growth, reproduction and morphology of Daphnia. Freshwat. Biol., 43, 19-29.

Declerck S., De Meester L., Podoor R. \& Conde-Porcuna J.M. 1997. - The relevance of size-efficiency to biomanipulation theory: a field test under hypertrophic conditions. Hydrobiologia, 360, 265-275.

DeMott W.R. 1982. - Feeding selectivities and relative ingestion rates of Daphnia and Bosmina. Limnol. Oceanogr., 27, 518-527.

Epp G.T. 1996. - Clonal variation in the survival and reproduction of Daphnia pulicaria under low-food stress. Freshwat. Biol., 35, 1-10.

Forbes V.E. \& Calow P. 1999. - Is the per capita rate of increase a good measure of population-level effects in ecotoxicology? Environ. Toxicol. Chem., 18, 1544-1556.

Glazier D.S. 1992. - Effects of food, genotype, and maternal size and age on offspring investment in Daphnia magna. Ecology, 73, 910926.

Gliwicz Z.M. 1990. - Food thresholds and body size in cladocerans Nature, 343, 638-640.

Gliwicz Z.M. \& Guisande C. 1992. - Family planning in Daphnia: resistance to starvation in offspring born to mothers grown at different food levels. Oecologia, 91, 463-467.

Guisande C. \& Gliwicz Z.M. 1992. - Egg size and clutch size in two Daphnia species grown at different food levels. J. Plankton Res., 14, 997-1007.

Hall D.J., Threlkeld S.T., Burns C.W. \& Crowley P.H. 1976. - The size-efficiency hypothesis and the size structure of zooplankton communities. Annu. Rev. Ecol. Syst., 7, 177-208.

Kammenga J.E., Busschers M., Van Straalen N.M., Jepson P.C. \& Bakker J. 1996. - Stress induced fitness reduction is not determined by the most sensitive life-history trait. Funct. Ecol., 10, 106-111.

Kooijman S.A.L.M. 1986. - Population dynamics on the basis of budgets. Pages 266-297 in The dynamics of physiologically structured populations. Metz J.A.J. \& Diekman O. (eds.). Springer Verlag, Berlin.

Kreutzer C. \& Lampert W. 1999. - Exploitative competition in differently sized Daphnia species: a mechanistic explanation. Ecology, 80, 2348-2357.

Lampert W. 2006. - Daphnia: model herbivore, predator and prey. Polish J. Ecol., 54, 607-620.

Lynch M. 1979. - Predation, competition, and zooplankton community structure: an experimental study. Limnol. Oceanogr., 24, 253-272.

Lynch M. 1989. - The life-history consequences of resource depression in Daphnia pulex. Ecology, 70, 246-256.

McCauley E., Murdoch W.W., Nisbet R.M. \& Gurney W.S.C. 1990. - The physiological ecology of Daphnia: development of a model of growth and reproduction. Ecology, 71, 703-715.

Meyer J.S., Ingersoll C.G., McDonald L.L. \& Boyce M.S. 1986. Estimating uncertainty in population growth rates: Jackknife vs. Bootstrap techniques. Ecology, 67, 1156-1166.

OECD 1998. - Daphnia magna reproduction test - Test guideline 211. Organization for the Economic Cooperation and Development, Paris.
Pereira J.L., Marques C.R. \& Gonçalves F., 2004. - Allometric relations for Ceriodaphnia spp. and Daphnia spp. Ann. Limnol., 40, 11-14.

Petrusek A., Bastiansen F. \& Schwenk K. 2005. - European Daphnia Species (EDS) - Taxonomic and genetic keys. [Build 2006-01-12 beta]. CD-ROM, distributed by the authors. Department of Ecology and Evolution, J.W. Goethe-University, Frankfurt am Main and Department of Ecology, Charles University, Prague.

Pierce C.A., Block C.A. \& Aguinis H. 2004. - Cautionary note on reporting Eta-squared values from multifactor ANOVA designs. Educ. Psychol. Meas., 64, 916-924.

Polishchuk L.V. \& Vijverberg J. 2005. - Contribution analysis of body mass dynamics in Daphnia. Oecologia, 144, 268-277.

Quinn G.P. \& Keough M.J. 2002. - Experimental design and data analysis for biologists. Cambridge University Press, Cambridge, $537 \mathrm{p}$.

Rinke K. \& Vijverberg J. 2005. - A model approach to evaluate the effect of temperature and food concentration on individual lifehistory and population dynamics of Daphnia. Ecol. Model., 186, 326-344.

Schwenk K. \& Spaak P. 1995. - Evolutionary and ecological consequences of interspecific hybridization in cladocerans. Experientia, $51,465-481$

Schwenk K., Posada D. \& Hebert P.D.N. 2000. - Molecular systematics of European Hyalodaphnia: the role of contemporary hybridization in ancient species. Proc. Roy. Soc. Lond. B, 267: 1833-1842.

Stein J.R. 1973. - Handbook of Phycological methods - Culture methods and growth measurements. Cambridge University Press, Cambridge, $448 \mathrm{p}$.

Stemberger R.S. \& Gilbert J.J. 1985. - Body size, food concentration and population growth in planktonic rotifers. Ecology, 66, 11511159.

Taylor B.E. \& Gabriel W. 1985. - Reproductive strategies of two similar Daphnia species. Int. Ver. Theor. Ang. Limnol., 22, 30473050 .

Taylor B.E. \& Gabriel W. 1992. - To grow or not to grow: optimal resource allocation for Daphnia. Am. Nat., 139, 248-266.

Tessier A.J., Henry L.L., Goulden C.E. \& Durand M.W. 1983. - Starvation in Daphnia: energy reserves and reproductive allocation. Limnol. Oceanogr., 28, 667-676.

Tessier A.J. \& Goulden C.E. 1987. - Cladoceran Juvenile Growth. Limnol. Oceanogr., 32, 680-686.

Tessier A.J. \& Consolatti N.L. 1991. - Resource quantity and offspring quality in Daphnia. Ecology, 72, 468-478.

Tessier A.J., Leibold M.A. \& Tsau J. 2000. - A fundamental trade-off in resource exploitation by Daphnia and consequences to plankton communities. Ecology, 81, 826-841.

Tessier A.J., Bizina E.V. \& Geeday C.K. 2001. - Grazer-resource interactions in the plankton: are all daphniids alike? Limnol. Oceanogr., 46, 1585-1595.

Tessier A.J. \& Woodruff P. 2002. - Cryptic trophic cascade along a gradient of lake size. Ecology, 83, 1263-1270.

Tillmann U. \& Lampert W. 1984. - Competitive ability of differently sized Daphnia species: an experimental test. J. Freshwat. Ecol., 2, 311-323.

Tilman D. 1980. - Resources: a graphical-mechanistic approach to competition and predation. Am. Nat., 116, 362-393.

Trubetskova I. \& Lampert W. 1995. - Egg size and egg mass of Daphnia magna: response to food availability. Hydrobiologia, 307 , 139-145.

Vanni M.J. \& Lampert W. 1992. - Food quality effects on life history traits and fitness in the generalist herbivore Daphnia. Oecologia, $92,48-57$. 
